\title{
The fuzziness of Montado landscapes: progress in assessing user preferences through photo-based surveys
}

\author{
T. Pinto-Correia $\cdot$ F. Barroso $\cdot$ D. Surová • \\ H. Menezes
}

Received: 28 October 2009/Accepted: 29 July 2010/Published online: 2 October 2010

(C) Springer Science+Business Media B.V. 2010

\begin{abstract}
The European Landscape Convention (2000) states that landscape is an important contributor to the quality of life for people everywhere and that landscape is a complex of natural and cultural factors, as they are seen by the observer. Landscape preference, i.e. the degree to which people like a landscape and variations in the same type of landscape pattern, is an emerging field of knowledge, still under development. Moreover, knowing how preferences of rural landscapes differ among stakeholders can help define and support management responses to the changing demands of modern society. There is a need to understand this demand for new uses and activities, such as hunting, leisure, recreation, life quality support, and aesthetic appreciation. In Mediterranean extensive land use systems, such as the Montado, where agricultural production is
\end{abstract}

T. Pinto-Correia · F. Barroso $(\bowtie) \cdot$ D. Surová ·

H. Menezes

Research Group on Mediterranean Ecosystems and

Landscapes (MEL), Institute of the Mediterranean

Agrarian and Environmental Sciences (ICAAM),

University of Évora, Pólo da Mitra, Edifício Principal -

Gab. 203, 204 e 205, 7000 Évora, Portugal

e-mail: flb@uevora.pt

T. Pinto-Correia

e-mail: mtpc@uevora.pt

D. Surová

e-mail: dj@uevora.pt

H. Menezes

e-mail: hgm@uevora.pt under threat, but where the demand for amenity functions is increasing, assessing preferences and thus what the public is looking for, is particularly relevant. This papers demonstrates how photo based surveys can be an suitable tool for assessing landscape preferences in Montado landscapes, and also that, in order to cope with the underlying fuzziness of these landscapes, the images need to be edited (manipulated) so that the variations shown to respondents are adequately controlled in the study. The methodological approach as well as the results, of two different studies on the users preferences for Montado landscapes, applied to case-study areas in the region of Alentejo, Portugal, are presented. The issues concerned with photo manipulation are a particular focus of discussion.

Keywords Landscape preferences .

Visualization tools - Photo manipulation .

Mediterranean landscapes ·

Photo-based enquiries · Landscape fuzziness

\section{Introduction}

As in other Mediterranean landscapes, the Montado system reflects a long history of human occupation, progressively adapting land use to the environmental potentialities and constraints (Pinto-Correia 1993; Pinto-Correia and Fonseca 2009). A complex agroforestry system, which is a combination of production 